\title{
Crítica ho POSTUlado POSITIVISTA da PSiCOlogia: DE Heidegger a Foucault
}

\author{
Rômulo Marques dos Santos Ballestê \\ Ricardo de Barros Cabral $\star$
}

\begin{abstract}
Resumo
A objetivação do ser humano, que segue os ideais de precisão das ciências físico-matemáticas, bem como a sua identificação com o fato biológico, orienta o projeto de ciência da psicologia, desde o século XIX. Michel Foucault aponta esta questão como um paradoxo. A redução do ser humano a objeto dado se mostra contrária às considerações de Martin Heidegger ao tratar do problema do Ser. Portanto, partindo das observações desses dois autores, será realizada uma crítica ao modelo positivista de cientificidade adotado no desenvolvimento da ciência psicológica moderna e, para, por fim, problematizar a ética que se supõe necessária nesta questão.
\end{abstract}

Palavras-chave: Psicologia; postulado positivista; Heidegger; Foucault.

\section{Critique to positivist postulate of the Psychology: From Heidegger to Foucault}

\begin{abstract}
The objectification of the human being in its psychological feature according to the ideals of accuracy of the physical-mathematical science, as well as its identification with the biological fact, guides the project of psychological science like a positive discipline since the nineteeth century. Michel Foucault pointed this question that a paradox. The reduction of the human being into an object of reveals itself to be contrary to the considerations of Martin Heidegger over the issue of the Being. Thus, starting by these authors observations, it will be made a critics to the positivist model of scientificity used in the development of the modern psychological science and lastly to bring to this debate the ethics which is believed to be necessary.
\end{abstract}

Keywords: Psychology; positivist postulate; Heidegger; Foucault.

\footnotetext{
^ Doutorando em Psicologia pelo PPGP da UFRJ, Professor de Psicologia no Instituto Brasileiro de Medicina e Reabilitacao. Praia de Botafogo, 158 - Botafogo, Rio de Janeiro - RJ.

E-mail: romuloballeste@gmail.com

$\star \star$ Doutor em Filosofia, atualmente é professor adjunto I da Universidade Federal do Rio de Janeiro. Av. Pasteur, 250 (Instituto de Psicologia) Botafogo/Urca - Rio de Janeiro, RJ - Brasil.

E-mail: ricardocabral@globo.com
} 


\section{INTRODUÇ̃̃o}

A psicologia moderna se inscreve no mundo no seio positivo dos saberes científicos, na época das técnicas e da industrialização numa relação de apreensão do fenômeno psicológico no qual seu projeto visa metodológico das ciências naturais e dos problemas colocados pelas dinâmicas no interior da sociedade. Assim, o percurso que a psicologia realiza apresenta caminhos de áreas dispersivas que estão ligadas aos problemas de natureza prática, de natureza da pesquisa laboratorial e a própria formação do psicólogo. Portanto, segundo Michel Foucault, esta natureza da psicologia evidenciam as contradições que se estabelecem no cruzamento de uma aplicabilidade com um pensamento, no imbricamento de uma técnica com discurso. A psicologia vai ser um conjunto de técnicas discursivas que intervêm diretamente no mundo.

A maneira como ela constitui o seu saber produz uma objetificação, naturaliza a dimensão para além do organismo objetificando o aspecto humano, produzindo assim modos de vida. O saber psicológico produz uma verdade sobre o homem, produz um homem, produz uma natureza do homem. Produz uma natureza no homem que o destaca do próprio sentido experiencial que atravessa a existência humana. $\mathrm{O}$ naturalismo fisicalista realizado positivamente nas formas objetivas do comportamento e da conduta a partir de estruturas matemáticas esconderia o paradoxo que aparece na ligação entre as instituições, o ensino e os direcionamentos dispersos do trabalho da psicologia. Dito de outra maneira, a forma experimental de metrificação da inteligência produzida por Binet servirá de instrumento de orientação clínica para a psiquiatria ao mesmo tempo em que estudos voltados para a orientação do trabalho, de desenvolvimento escolar e pedagógico, orientação profissional. A orientação de grandes laboratórios de psicologia industrial voltados para questões ergonométricas estabelecerão inúmeras pesquisas psicofisiológicas que determinarão modos de produção.

Para Seguiremos os caminhos ofertados por dois pensadores contemporâneos. Um deles é o francês Michel Foucault a partir dos trabalhos, da década de 1950, que pretendem investigar as condições histórico-filosóficas de possibilidade dos saberes sobre o homem, em especial a psicologia - estabelecendo como ponto de seu fundamento as "contradições" contidas entre seu projeto científico e seus postulados. O outro é o alemão Martin Heidegger com sua crítica à metafísica ocidental que levou ao que chamou de esquecimento do ser, uma objetificação do Ser, e à técnica moderna. Tal esquecimento teve seu início já na Grécia Antiga, não sendo, portanto, algo exclusivo da Modernidade, embora se intensifique neste período. O pensamento Moderno empreendeu uma nova interpretação do ente na sua totalidade. Esse pensamento concebe o homem como Vohandenheit, termo destacado na nota explicativa (N8) (HEIDEGGER, 1998, p. 311) atribuída à edição brasileira de Ser e Tempo, parte I, e refere-se a um "objeto simplesmente dado" no mundo. Heidegger aborda nitidamente esse ponto em seus Seminários de Zollikon, na casa do psiquiatra suí- 
ço Medard Boss, os quais marcam a presença da analítica existêncial no campo das ciências da alma fornecendo um instrumento para a crítica de pressupostos metafísicos da psiquiatria, psicanálise e da psicologia.

Márcia de Sá Cavalcanti, tradutora de Ser e Tempo, de Martin Heidegger, estabelece esta nota (N1) - à Parte I, nas pp. 309-310, da $1^{\text {a }}$ edição brasileira, pela Editora Vozes, de Petrópolis - Rio de Janeiro, de 1988, para o termo alemão $D a$ sein, de difícil tradução, optando por pre-sença de difícil tradução, e fundamental importância para a filosofia heideggeriana. Tomando como base um entrevista de Heidegger ao Der Spiegel (1977), ele pode expõe algumas razões para a escolha da tradução do termo alemão por pre-sença. Encontramos em uma das quatro razões um ponto de tangência com o trabalho foucaultiano. Citamos abaixo parte da nota explicativa referente ao termo Dasein.

Pre-sença não é sinônimo nem de homem, nem de ser humano, nem de humanidade, embora conserve uma relação estrutural. Evoca o processo de constituição ontológica de homem, ser humano e humanidade. É na pre-sença que o homem constrói o seu modo de ser, a sua existência, a sua história, etc. (HEIDEGGER, 1998, p. 309).

O pensamento de Heidegger, a partir de sua crítica historial-ontológica fundamental, na sua crítica à metafísica, coloca e acentua a necessidade da proposição do questionamento do ser. A pergunta pela origem, pelo desvelamento da "essência", remete à interrogação fundamental de toda analítica existencial de Ser e Tempo, obra "angular" na reviravolta da filosofia atual. A indagação pelo sentido do ser se coloca como um ponto de extrema importância para a compreensão da humanidade como ser no mundo, que acontece no mundo, imerso na "tessitura existencial da experiência". (STEINER, 1990, p. 76). Retornaremos a Foucault em sua perspectiva crítica para além da referência ontológica ao Ser, o que em seu pensamento se exprime pelos paradoxos existentes no modo que o homem constrói o seu modo de ser, sua própria história.

Dessa forma, afirmação de Foucault, de que "Não haveria psicologia possível a não ser pela análise das contradições da existência do homem e pela retomada do que há de mais humano no homem, isto é, sua história" (FOUCAULT, 1957a, p. 128). Portanto, este caráter historial coloca um ponto de ligação entre o pensamento de Michel Foucault e o pensamento de Martin Heidegger permitindo a articulação, pretendida neste trabalho, para discutirmos a psicologia moderna. O pensamento de Heidegger, a partir da sua crítica historial-ontológica fundamental, na sua crítica à metafísica, coloca e acentua a necessidade da proposição do questionamento do ser. A pergunta pela origem, pelo desvelamento da "essência" remete à pergunta norteadora de toda analítica existencial de Ser e Tempo, obra fundamental dentro da história da filosofia ocidental. A pergunta pelo sentido do ser se coloca como um ponto de extrema importância para a compreensão do homem como um ser acontecente no mundo, imerso na "tessitura existencial da experiência" (STEINER, 1990, p. 76). 


\section{A Psicologia Moderna: contradições entre projeto e postulados}

O pensador francês, Michel Foucault, dedicou-se à questão das ciências humanas em diversos textos do início da sua produção literária, décadas de 1950 e 1960. O surgimento moderno de um saber sobre o homem e a própria constituição deste homem enquanto um duplo empírico-transcendental (FOUCAULT, 2007) figuram as discussões que colocam em cena uma constituição arqueológica, isto é, que coloca em cena as condições de possibilidade de emergência de um saber nos interstícios de diversas práticas discursivas. Os primeiros trabalhos de Foucault que foram publicados revelavam um grande interesse nos saberes que não possuem autonomia e não são pensados, pelo autor, por um caminho que liga sucessivos elos numa história das ideias científicas. A psicologia, a psiquiatria, a loucura, o direito, a sexualidade, por exemplo, serão criticamente. Interessa-nos discutir o campo da psicologia moderna a partir do efeito produzido pela historiografia bastante difundida através de manuais de psicologia que organiza o curso da psicologia, desde o seu aparecimento, pelo caminho epistemológico cientificista. Foucault ajuda-nos a pensar sobre a psicologia e os efeitos de naturalização do psiquismo e da própria subjetividade. Podemos encontrar nas palavras do autor uma crítica à exigência de um naturalismo biológico para compreendermos os fenômenos psicológicos.

É preciso encontrar um estilo de coerência psicológica que autorize a compreensão dos fenômenos mórbidos sem tomar como modelo de referência estágios descritos à maneira de fases biológicas. É necessário encontrar o centro das significações psicológicas a partir do qual, historicamente, ordenam-se as condutas mórbidas. (FOUCAULT, 1984, p. 52).

A psicologia enquanto um saber que surge na Idade Moderna se estrutura nas contradições estabelecidas entre os postulados metodológicos e o projeto moderno inaugural de cientificidade. Encontramos na historiografia da psicologia (HALL, 1912, MURPHY, 1971, BORING, 1979, MYERS, 2006) um conjunto de esforços intelectuais na direção da constituição da psicologia enquanto uma ciência autônoma, durante o século XIX, amparados no crescimento da influência empirista ao mesmo tempo em que no fortalecimento de filosofias materialistas e positivistas. Assim, a psicologia fundamenta, epistemologicamente, sua investigação no modelo físico-químico tendo a pretensão de inserir-se no escopo das ciências naturais enquanto "ciência de um objeto natural" (CANGUILHEM, 1973, p. 109). A palestra de Georges Canguilhem, que coloca de maneira precisa o problema da unidade da psicologia e apresenta o surgimento e o desenvolvimento da fisiologia dos sentidos, no século XIX, na busca de promover um alinhamento da psicologia com as ciências naturais na fundamentação dos fenômenos naturais em leis e princípios que regem o homem e sua vida. Portanto, a psicologia irá nortear o rumo de seu desenvolvimento pela objetividade, pelo diagrama analítico, que toma a explicação dos fenômenos psíquicos pelas fórmulas físicas que regulariam o humano, doravante reduzido 
ao organismo e suas propriedades físico-biológicas. Segundo Canguilhem, na configuração deste projeto "[...] ela [a psicologia] deve procurar numa natureza, isto é, na estrutura do corpo humano, a razão de existência dos resíduos irreais da experiência humana" (CANGUILHEM, 1973, p. 110). Portanto, tal esforço de racionalização da psicologia para torná-la uma ciência autônoma, isto é, uma ciência amparada por coordenadas metodológicas existentes no trabalho das ciências da natureza, gera como efeito a naturalização do homem.

A psicologia irá identificar na física o guia para se desenvolver e legitimar, pelo diagrama analítico e por coordenadas metodológicas que imagina serem as utilizadas nas ciências ditas naturais, e a partir desses referenciais advogará sua causa pela naturalização (física) do humano. Seu projeto consistiria simplesmente em entender que "[...] [a psicologia] deve procurar numa natureza, isto é, na estrutura do corpo humano, a razão de existência dos resíduos irreais da experiência humana." (CANGUILHEM, 1973, p. 110). Em outras palavras, explicar o irredutível à física pela física. Sem nos referirmos à existência de uma realidade sobrenatural à parte, a alma, por exemplo, só nos restaria decidir a questão do irreal por um recurso ao físico ou à física, à bioquímica cerebral? Se a psicologia renuncia ao objeto que a etimologia lhe confere, e diversos trabalhos, no contexto do século XIX e início do século XX, apresentam esta direção, como, por exemplo, o livro de Nicolas Kostyleff, Les Substituts de l’ame dans la Psychologie Moderne, de 1906, que já deixa claro quanto ao projeto científico da psicologia moderna radicalmente desvinculado de qualquer especulação filosófica. Podemos citar outros trabalhos que seguem nesta mesma direção: (DELBOUEF, 1876, 1883; MAUDSLEY, 1870).

O único caminho a seguir é o da física? Como se fossemos constrangidos a escolher entre duas realidades: espiritual ou física? Assim,

[...] o trabalho real da pesquisa psicológica não é a emergência de uma objetividade nem o fundamento ou o progresso de uma técnica: nem a constituição de uma ciência nem a revelação de uma forma de verdade. Ao contrário, seu movimento é o de uma verdade que se desfaz: de um objeto que se destrói; de uma ciência que busca somente desmistificar-se: como se o destino de uma psicologia que se queria positiva, e considerou a positividade do homem no plano de suas experiências negativas, fosse paradoxalmente de só fazer uma tarefa científica inteiramente negativa (FOUCAULT, 1994[1957b], p. 157).

A aceitação deste dilema inscrever-se-á sob esta forma de determinismo causal que estabelece a reificação do ser humano na estrutura do pensamento científico, ou seja, estabelece a redução da dimensão psicológica à dimensão física numa espécie de naturalismo fisicalista. Entendemos que as leis e os progressos físico-químicos tal como compreendidos por uma filosofia positivista da ciência passam a submeter toda a vida ao que pode ser calculado. Este modelo calcado em tais leis se estende aos estudos de psicopatologia e psicofisiolo- 
gia. As investigações estruturais do funcionamento neurofisiológico repousam na suposição de um mecanicismo interacionista que estabeleceria a correspondência entre duas naturezas distintas e interdependentes, ou seja, as ações orgânicas e relações materiais influem decisivamente na clareza e na distinção das ideias e do psíquico em geral.

Foucault, ao adotar uma concepção fenomenológica e existencial, nos seus primeiros trabalhos (FOUCAULT, 1984), interessa-se pelas ciências humanas e seu caráter de "disciplinas duvidosas". Os saberes das ciências naturais estabelecem uma unidade entre a determinação de uma causalidade e a formulação abstrata válida. Esta unidade é o próprio efeito de verdade que não comparece quando se trata das ciências humanas deixando sua constituição "duvidosa". As contradições saltam aos olhos quando psicologia e prática se imbricam neste positivismo que supõe responder as exigências paradoxais de "aplicação" para atender as questões provenientes do dia a dia do convívio social. A impostura do uso das ciências físicas, a biologia aí compreendida, é flagrante. Sua ingerência na prática revela a natureza obscura de seu afazer, e manifesta as exigências que delineiam o campo da psicologia: exigências em conflito que se deparam com o limiar tênue entre o normal e o patológico ou, ainda, estabelece a normalidade a partir da anormalidade. A psicologia cumprirá uma função normatizadora como um efeito de sua própria natureza. A psicologia é, segundo as palavras de Foucault,

[...] em sua origem, uma análise do anormal, do patológico, do conflito, uma reflexão sobre as contradições do homem com ele mesmo. E se transformou numa psicologia do normal, do adaptado, do ordenado, foi de uma maneira secundária, num esforço para dominar essas contradições (FOUCAULT, 1994[1957a], p. 122).

A dimensão psíquica é tomada por um conjunto orgânico dotado de processos e regulações internas envolvendo a capacidade de adaptação. Todavia, a matematização das funções do organismo a partir da noção de curva normal é transposta da exigência de precisão dos parâmetros biológicos à regulação naturalista das pessoas vivendo em sociedade. Encontramos na palestra de Canguilhem acerca da psicologia uma linha epistemológica que se aproxima bastante do caminho seguido por Foucault em seus trabalhos iniciais cujo interesse, voltado para as ciências humanas, é bastante evidente e o esforço para indicar que, no humano, há uma dimensão para além do orgânico. Assim, as palavras de Canguilhem nos ajudam nesta discussão.

No homem, o relacionamento das formas fisiológicas com a diversidade dos modos de reação e de comportamento que dependem, por outro lado, de normas culturais, se prolonga, naturalmente, pelo estudo das situações patogênicas especificamente humanas. No homem, ao contrário do animal de laboratório, os estímulos ou agentes patogênicos jamais são recebidos pelo organismo como fatos físicos em estado bruto, mas são também experimentados pela 
consciência como sinais de tarefas ou de provas a serem realizadas (CANGUILHEM, 1990, p. 245-246).

O rigor da objetividade e exatidão necessários ao enquadramento do seu objeto, conferido pelos procedimentos oriundos das ciências físicas, indica a necessidade de reconhecer um sujeito da experiência numa realidade histórica e singular não mais objetiva, física ou mecanicamente quantificável, pelo reducionismo positivista. Como afirma Foucault, "A psicologia [...] nasce naquele ponto em que a prática do homem encontra sua própria contradição". (FOUCAULT, 1994[1957a], p. 122). O humano não está mais somente inscrito na ordem natural. Esse reconhecimento coloca como importante a consideração de que há algo para além da possibilidade de apreensão dada pela objetividade. O erro e as ilusões do espírito no seu trilhar histórico irrompem, e essa dimensão irredutível e imanente ao modo de ser do humano ganha importância. Afasta-se, então, a exigência de objetividade naturalista que fundava o estatuto epistemológico das concepções positivista e materialista da psicologia, expondo as tensões e a contradição entre seu projeto de ciência e seus próprios postulados.

Foucault ainda nos indica duas transformações importantes no campo da psicologia: a legitimidade adquirida pela biologia no rol das ciências modernas, e a dimensão da significação introduzida pela psicanálise. É a partir da importante obra de Charles Darwin, A Origem das espécies, (1842) que o evolucionismo se coloca como um modelo de explicação do humano. A tese evolucionista, de Darwin, transformada por Spencer, reivindica o mesmo status da física newtoniana. O humano passa a ser pensado, portanto, sob esse prisma evolucionista. "A evolução do indivíduo foi descrita ao mesmo tempo como um processo de diferenciação - movimento horizontal de expansão para o múltiplo - e como um movimento de organização hierárquica vertical de integração na unidade" (FOUCAULT, 1994[1957a], p. 125). Integrando o atual e o anterior, o presente e o passado, numa unidade desprovida de contradição e conflito, imaginou-se a possibilidade de escrever a história a partir de estruturas hierarquicamente organizadas do mais simples para o mais complexo, no sentido de uma linearidade progressiva, que reverberou não só pela biologia, mas, também, pela psicologia e pela sociologia. Nas palavras de Foucault podemos entender que

[...] a importância do evolucionismo na psicologia é devido a ele ter sido, sem dúvida, o primeiro a revelar que o fato psicológico só tem sido em relação a um futuro e a um passado; que seu conteúdo atual repousa sobre um fundo silencioso de estruturas anteriores que o preenchem com a história, mas implica ao mesmo tempo um horizonte aberto sobre o eventual (FOUCAULT, 1994[1957a], p. 125).

Este horizonte aberto sobre o eventual coloca um problema para as significações ideias que aparecem no trabalho histórico que persegue o problema da origem com a suposição de encontrar constâncias no homem. Mas, pode ser encontrada uma transformação nesta busca por constâncias e linearidades naturalizadas pelo discurso do cientificismo em psicologia, na inclusão da significação. 
Essa transformação, oriunda do seio da psicanálise, redimensionou a orientação da vida. Esse sentido é dado por Freud ao conceber as significações objetivas como a orientação dos fatos psíquicos. E, portanto, para Foucault, "[...] é no curso da reflexão freudiana que a análise causal transformou-se em gênese das significações, que a evolução deu lugar à história e que o recurso à natureza foi substituído pela exigência de analisar o meio cultural" (FOUCAULT, 1994[1957b], p.154). A introdução da perspectiva debruçada sobre o humano e sua conduta, ambos imersos na cultura, que considera com maior rigor a realidade humana, estabelece um alargamento nas linhas divisórias do saber. Assim, nas palavras de Foucault:

A reviravolta através da qual a natureza, como negação da verdade do homem, se torna para e pela psicologia o próprio solo de sua positividade, da qual o homem, em sua existência concreta, se torna por sua vez a negação, esta reviravolta, operada pela primeira vez de um modo explícito por Freud, é agora transformada na condição de possibilidade de qualquer pesquisa em psicologia. Considerar a negatividade do homem por sua natureza positiva, a experiência de sua contradição pelo desvelamento de sua verdade mais simples, mais imediata e mais homogênea é, desde Freud, o projeto, no mínimo silencioso, de qualquer psicologia (FOUCAULT, 1994[1957b], p. 154).

A psicologia mantém a sua trajetória na direção da positividade denunciada por Foucault. Pretendemos até aqui apresentar a direção do projeto de psicologia moderna e esforço de clareza nos estudos da consciência sem considerar o destacamento da psicologia do campo da ciência. Para nós, os efeitos de uma psicologia, sobretudo, de uma historiografia da psicologia que toma a origem deste saber num fundamento experimental e tem seu sentido orientado pela filosofia positivista serão articuladas com as críticas feitas pelo filósofo, Martin Heidegger, aos efeitos da metafísica e à técnica moderna no que diz respeito ao esquecimento ao modo da pre-sença do ser. É, principalmente, na crítica que Heidegger faz ao efeito de objetificação deste modo de ser-no-mundo produzido pela técnica moderna que dialóga com nosso trabalho.

\section{Heidegger e a Psicologia Moderna}

Em sua obra, Martin Heidegger aponta a dependência ou filiação que as teorias psicológicas carregam da tradição do pensamento ocidental. O caráter da coisificação mostra-se evidente na tentativa destas teorias, que constituem a psicologia moderna, em determinar uma objetivação material do homem, o que compreende a justificativa e a limitação deste saber. "A justificativa da Psicologia consiste no fato de que ela reconheceu algo 'não-material', e sua limitação é que ela queria determinar isto pelo método da pesquisa material das ciências físicas" (HEIDEGGER, 2001, p. 229; grifo nosso). 
Se, contudo, o intento do saber psicológico moderno era afastar-se da especulação metafísica, empreendendo modelos metodológicos oriundos das ciências físicas, parece-nos que aí podemos encontrar as contradições de que nos falava Foucault. Estes modelos enxergarão o homem como uma natureza empreendendo, por conseguinte, um deslizamento na direção da objetificação (LOPARIC, 2004). Para Heidegger, a história da Metafísica levou à coisificação, que mais tarde fora apropriada pela ciência moderna e depois pela técnica, a partir do início do século XX. O ocultamento do sentido da pergunta pelo ser, lançado pela história da metafísica, e que estabelece a noção de homem como natureza, pavimentou a senda ontológico-objetivante que atravessa a metafísica medieval e logo adiante as ciências até ser dominada "nos dias de hoje" pela técnica. O objetivo de Heidegger é uma "cruzada contra a objetificação" (LOPARIC, 2004, p. 43), metafísica, científica ou técnica.

A psicologia, ao se pretender científica de acordo com a ideia moderna de ciência (cálculo e verificação), deixa escapar algo fundamental. $\mathrm{O}$ rigor de seu próprio método solidarizou a psicologia com o preceito, ou talvez, com o preconceito fisicalista, o que a levou ao abandono da tarefa de responder às suas contradições seminais. Não pôde deixar de fora, portanto, aquilo que justamente constitui o problema da psicologia, ou melhor, a constitui como "ciência" paradoxal: impossibilidade de atender à exigência de objetivação contida no projeto da psicologia como ciência no sentido moderno. É justamente aquilo que escapa à cadeia científica de raciocínios que funda (Grund) a psicologia: aquilo que escapa à apreensão formal e reducionista do esquadrinhamento estatístico e psicométrico ampara o projeto científico da psicologia.

Heidegger (1973), em sua carta a Jean Beaufret, em resposta ao trabalho de Jean-Paul Sartre, afirma:

O corpo do homem é algo essencialmente diferente do organismo animal. $\mathrm{O}$ erro do biologismo não está superado quando se junta ao elemento corporal do homem a alma, e à alma o espírito, e ao espírito o aspecto existencialista (o aspecto ôntico da existência), pregando ainda mais alto que até agora o grande apreço pelo espírito, para então, contudo, deixar tombar tudo de volta para a vivência da vida, admoestando-se ainda como ilusória segurança, que o pensar destrói, pelos seus conceitos rígidos, o fluxo da vida e que o pensar do ser deforma a existência. $\mathrm{O}$ fato de a fisiologia e a química fisiológica poderem examinar o homem como organismo, sob o ponto de vista das Ciências da Natureza, não é prova de que neste elemento "orgânico", isto é, de que no corpo explicado cientificamente, resida a essência do homem (HEIDEGGER, 1973, p. 352-353). 
A psicologia não se torna menos importante por se constituir nessa incompletude apreensiva. A dimensão própria do humano aparece e evidencia "algo" para além do aparato tecnológico e irrompe com o empenho da objetificação científica. No entanto, o delineamento do objeto da psicologia moderna, que não é um objeto mas, em última análise uma pessoa, esteve abordado desde sempre da perspectiva de sua naturalização. $\mathrm{O}$ trabalho da psicologia foi orientado por um esforço de objetificação do homem resultando na naturalização deste.

A filosofia de Heidegger entende o homem como tendo o modo de ser Dasein e, portanto, um modo de "ser com as pessoas que vêm ao seu encontro, nunca como um sujeito existente para si" (HEIDEGGER, 2001, p. 182), Heidegger confere às "relações" um notável grau de relevância e compreende a possibilidade do modo de ser do homem em relação com outros entes e consigo próprio. Dessa maneira, acreditamos que isso nos permitirá introduzir a distinção de dois conceitos que fazem parte dos trabalhos de Heidegger, e nos ajudará a nos debruçar sobre essa questão que nos acossa, a naturalização causada pela atividade da psicologia moderna.

São os conceitos de Vohandenheit e Zuhandenheit. O primeiro, Vorhanden, pode ser entendido como algo objetivamente dado, algo simplesmente dado, como o caráter de "presença próxima" que possui o objeto "aí". Entretanto, o segundo, Zuhanden (valemo-nos, mais uma vez, aqui (N17) (HEIDEGGER, 1998, p. 314), das notas explicativas da tradutora da edição brasileira de Ser e Tempo - Márcia de Sá Cavalcanti) deve ser compreendido como acessibilidade imediata, manualidade, ao alcance da mão, ou ainda, pelo termo das zuhandene Welt, que se entende como "o mundo que está à mão".

Acreditamos que as imagens encontradas por George Steiner para marcar a diferença entre os termos alcançam a precisão de sutileza e força que os termos mesmos carregam contribuindo para a compreensão desses termos e a utilização dos mesmos em nosso trabalho. Afirma Steiner (1990, p. 77-78) que

[...] a natureza é Vorhanden para o físico, e as rochas são vorhanden para os geólogos. Mas não é assim como um pedreiro ou um escultor recebe uma rocha. A sua relação com a pedra, a relação crucial para o seu Dasein, é a de Zuhandenheit, de uma acessibilidade imediata.

Sem considerarmos a problematização ontológico-fundamental que Heidegger nos apresenta, a reificação do homem enquadrar-se-á como decorrência óbvia desta atividade pseudocientífica e naturalista. E a psicologia seria a ciência naturalmente destinada a essa tarefa produzir um efetivo reducionismo do psíquico no materialismo físico. No entanto, "[...] só ele [o homem] experimenta a existência como problemática, só ele é uma presença ôntica buscando uma relação de entendimento ontológico com o próprio ser" (STEINER, 1990, p. 72). No processo da sua existência o homem realiza a sua humanidade. É situando-se 
numa imanência do mundo, numa imersão no mundo, numa imanência radical que o homem se configura como um ente-no-mundo, um ente que questiona o seu ser, um ser-no-mundo (In-der-Welt-sein).

A analítica heideggeriana nos propõe enxergar o homem a partir do ato de existir como sua estrutura fundamental: a "presentificação do ato de existir" (KOYRÉ, 1991, p. 215-216), esse modo de ser do homem é compreendido por Ek-sistenz. Tal modo contraria a visão de homem como um objeto. Pensar o homem implica necessariamente o relacionar deste com os entes e consigo mesmo. Compreender o ser é relacionar-se, fundamentalmente consigo mesmo. Isto coloca o homem no existir. A pre-ocupação (fürsorge), que consiste na pre-sença, se dá imanentemente imbricada nas relações estabelecidas e extendidas a outras coisas, a outros entes, assim como com o seu próprio ser, ou seja, consigo mesmo, configurando essencialmente na existência o modo de "se preocupar com" (besorgen). O homem se constitui tecendo a própria existencialidade com longos fios de incerteza, na postulação do sentido imanente ao ser, na própria questionabilidade desse sentido do ser. "A questionabilidade da acontecência do ser define o homem," (SARTRE, 2004, p. 61).

Ao invés de questioná-lo, concebeu-se o ser do homem como "evidência", no sentido de ser simplesmente dado [Vorhandenheit] junto às demais coisas criadas. [...] A mesma coisa vale para a "psicologia", cujas tendências antropológicas não se podem mais desconsiderar, [...] A falta de fundamentos ontológicos, entretanto, não pode ser compensada inscrevendo-se a antropologia e a psicologia numa biologia geral (HEIDEGGER, 1998, p. 86).

O problema da objetificação do homem dentro do campo de pensamento da psicologia direciona para a dimensão da "cura", e novamente as imagens da relação que se estabelece nos termos anteriormente apontados (Vorhandenheit e Zuhandenheit) aparecem.

Se a relação da psicologia com o homem é conferida por uma estruturação baseada na posição moderna que concebe o homem apenas como um ente simplesmente dado, como Vorhandenheit, ela coloca-se então, diante do exercício dessa relação qual o geólogo diante da rocha (que interroga as leis que estruturam este ente), ou qual o físico que apreende objetivamente, por mensurações instrumentais e elabora formalmente a natureza. $\mathrm{O}$ encetamento realizado pela pergunta que Heidegger coloca em uma de suas aulas em Zollikon: "até onde isto nos leva perante uma pessoa doente? Fracassamos!" (HEIDEGGER, 2001, p. 47) parece-nos de extrema relevância. Até onde nos é permitido pensar o sofrimento do humano se concebemos apenas a dimensão de organismo compreendida no homem, se empreendemos uma pesquisa necessariamente localizada no cérebro, no organismo sob a forja do esquadrinhamento psicopatológico? Se supusermos que no funcionamento fisiológico se ampara ou mesmo reside a totalidade da vida psicológica será entendido por "cura" (Heil) o ato ou o movimento de colocar o ente "são, sanado, integro" (Heilsamen). Restabelecer a integridade de outrora 
deverá ser a finalidade. Porém, se o entendimento de "cura" eclipsa a pergunta fundamental de Heidegger pelo sentido do ser, a dimensão ética é convocada a comparecer a esta problematização. Na verdade, ela sempre esteve presente. Ao colocar a possibilidade de pensar a psicologia como domínio que concebe o homem numa relação fundamental para o seu ser-no-mundo, como uma acessibilidade imediata, retira-se a ética das sombras e do silêncio a que lhe foram reservados toda objetificação. A manualidade, enquanto uma relação que não pode ser suposta como previamente dada, não pode ser tomada como evidência, no sentido de um objeto simplesmente dado. A psicologia não pode ser uma biologia do espírito. A ética, portanto, não pode ser deslocada de todo esse campo de discussão.

É o caráter da responsabilidade que pretendemos inserir quando falamos de ética. Essa responsabilidade que aponta imediatamente para a concepção de cura diz respeito automaticamente à psicologia, a sua clínica, à produção de saberes, de formas de subjetividade, às produções de modos de vida. Aponta a dimensão de intervenção e de implicação inerente à psicologia, uma dimensão política. Portanto, para Heidegger, uma vez "colocada efetivamente a pergunta "o que é o homem?" entrega de maneira expressa a responsabilidade do homem o seu ser-aí. Esta responsabilização pelo ser-aí é o index da "finitude" que lhe é intrínseca (HEIDEGGER, 2003, p. 322-323). É a imagem da relação da rocha para o escultor que se configura imediatamente sob o plano da ética. $\mathrm{O}$ homem não é entendido como uma rocha, tampouco o psicólogo um escultor, nem a psicologia uma arte de entalhar. Mas pretendemos realçar a possibilidade dessa relação que concebe algo para além da dimensão natural, da dimensão do organismo, em que a psicologia moderna se fundou. A psicologia tentará resolver a contradição entre a apreensão do homem a partir da referência às ciências físicas e a sua existência na trama social, seu emaranhado histórico? Todas as tentativas de superação dessas contradições congênitas da psicologia fracassam em seu plano, pois as contradições se apresentam como próprias do humano, coextensivas à existência humana, inerentes ao modo de ser do humano e, no máximo podem ser mascaradas, deslocadas, postas como falsos problemas.

\section{Conclusão}

Será possível pensar as pessoas e a dimensão do humano de outra maneira sem enquadrá-las em padrões preestabelecidos que se presumem científicos? Há chance para a psicologia fora dos esquadros de um saber decalcado da física, exclusivamente preocupado com a medida? Em suma, pensar de uma maneira que não se resuma à norma do que vulgarmente se entende por ciência e aceita complacentemente, hoje ainda é possível?

As chamadas neurociências são um misto contraditório e perigoso de questões científicas e éticas, ora descrevendo a atividade do organismo em seus mecanismos fisiológicos de regulação na constante mudança em função do meio; ora descrevendo patologias mentais a partir de coleções de sinais e sintomas; ora descrevendo pretensos valores constituintes da essência do homem, da natureza humana que são apenas o resultado de sua própria apli- 
cação. Contudo, pretendem resolver o paradoxo e a contradição inerente à psicologia moderna. Pode-se encontrar uma bom posicionamento crítico, bastante atual, acerca das neurociências no trabalho de Ehremberg (2009). Em verdade, impõem normas, executam normalizações através de intervenções medicamentosas, entre outras práticas obscuras e a isso denominam progresso. Bem como parece para Bordeau $(1999$, p. 63$)$ que é:

Inútil retraçar os avatares da inteligência articificial na
segunda metade do século. Além de a história já ter sido
contada, os desdobramentos de esperanças e decepções,
de promessas quebradas e de confusão conceitual a que ela
se resume, pouco sofre da comparação com o que precede.
Durante muito tempo, a receita consistiu, em uma mistura de
informática, lingǘstica e de psicologia que pode facilmente
ludibriar, e que alguns trabalhos de Chomsky dão uma
imagem suficientemente boa. Mas desde há algum tempo,
passou-se da IA às Ciências cognitivas, depois das ciências
cognitivas as neurociências. A maneira como as idéias se
desvalorizam bastaria por si só para despertar suspeitas. Tais
mudanças incessantes, onde alguns querem ver o indício
tangível de um progresso representam, antes uma fuga
adiante, uma maneira de eludir as dificuldades fazendo crer
que alguma coisa está acontecendo.

A normalização se torna a efetiva finalidade da intervenção na relação fundamental da pessoa com as coisas, consigo própria e com sua situação sócio-histórica. Dessa maneira, as realizações da psicologia têm um enraizamento ético-político ao encarnar implicações diretas na vida cotidiana. Repensar a psicologia é necessariamente repensar a ideia de humanidade implicada nesta textura ética, política e jurídica.

O permanente retorno às vias do naturalismo e do reducionismo fisicalista já criticados à exaustão e o esforço vazio de furtar-se à contradição inerente a este projeto nos revelam que não estamos mais no plano do argumento e das objeções. A maneira como se insiste nisso, de uma maneira generalizada, seja na mídia ou nas diretrizes de uma pesquisa científica parece não passar de um empreendimento que consiste em incrementar as estratégias de coerção e correção, de enquadramento da exceção. As pesquisas progridem no sentido de executar este fim sem dor. Executar a reificação bem sucedida diretamente ligada a um esforço de normalização por parte de instâncias políticas e econômicas, médicas e jurídicas no corpo social.

Eis a razão pela qual não basta mais reivindicar o homem no seio da $E k$ sistenz interrogando um sentido em seu caráter ontológico, enquanto ser-no-mundo, como aquele que inventa a sua própria história. Não basta o argumento ou a análise de uma condição demasiado geral. Ao mesmo tempo em que inventa sua história e a cultura na qual está imerso, ele padece deste saber fossilizado de onde é convocado a responder. 
Impossível pensar o que concerne o humano senão a partir desta exigência: exigência ética e política na qual qualquer um pode e deve estar implicado, e, por isso mesmo, deve ser pensado. Para tanto, não se pode toldar essa dimensão em nome de uma suposta cientificidade, problema que renascerá, como na hidra de Lerna, a cada vez que nos esquecermos desta verdade fundamental: jamais ultrapassar a contradição inerente a este projeto que pretende responder questões próprias do cotidiano mimetizando e simulando procedimentos próprios à ciência moderna.

\section{REFERÊNCIAS}

BORDEAU, M. Pensée symbolique et intuition. Paris: PUF, 1999.

BORING, G. Historia de la psicologia experimental. México: Trillas, 1979.

CANGUILHEM, G. O que é psicologia? Revista Tempo Brasileiro, Rio de Janeiro, n. 30/31, p. 104-123, jul-dez, 1973.

CANGUilheM, G. Etudes d'Histoire et des Philosophies des Sciences. Paris: Vrin, 1989.

CANGUILHEM, G. O normal e o patológico. Rio de Janeiro: Forense Universitária, 1990.

DELBOUEF, J. La Psychologie comme Science de l'ame: son present et son avenir. Bruxelles: C. Muquardt, 1876.

DELBOUEF, J. Examen Critique de La Loi Psychophysique: sa base et sa signification. Paris: Germer Baillière, 1883.

EHRENBERG, A. O sujeito cerebral. Psicologia clinica. v. 21, n. 1, p. 187-213, 2009.

FOUCAULT, M. La psychologie de 1850 à 1950 (1957a). In: D. DÉFERT, D.; EWALD, F. Dits et Ecrits (pp. 120-137). Paris: Gallimard, 1994.

FOUCAULT, M. La recherche scientifique e la psychologie (1957b). In: DÉFERT, D.; EWALD, F. Dits et Ecrits (pp. 137-158). Paris: Gallimard, 1994.

FOUCAULT, M. Doença Mental e Psicologia. Rio de Janeiro: Tempo Brasileiro, 1984.

FOUCAULT, M. As Palavras e as Coisas. SãoPaulo: Martins Fontes, 2007.

HALL, G. Founders of Modern Psychology. New York/London: Appleton and Company, 1912. 
HEIDEGGER, M. Carta sobre o Humanismo. In: HEIDEGGER, M. Os Pensadores. Abril Cultural: São Paulo, 1973.

HEIDEGGER, M. Ser e Tempo. Petrópolis: Vozes, 1998.

HEIDEGGER, M. Seminários de Zollikon. Petrópolis: Vozes, 2001.

HEIDEGGER, M. Os conceitos fundamentais da metafísica: mundo, finitude, solidão. Rio de Janeiro: Forense, 2003.

KOSTYLEFF, N. Les Substituts de l'ame dans la Psychologie Moderne. Paris: Félix Alcan, 1906.

KOYRÉ, A. Estudos de História do Pensamento Filosófico. Rio de Janeiro: Forense Universitária, 1991.

LOPARIC, Z. Heidegger. Rio de Janeiro: JZE, 2004.

MAUDSLEY, H. Physiologie de l'Esprit. Paris: C. Reinwald, 1870.

MURPHY, G. Introducción histórica a la psicologia contemporânea. Buenos Aires: Paidós, 1971.

MYERS, G. Psicologia. Rio de Janeiro: LTC, 2006.

SARTRE, J. P. O Existencialismo é o Humanismo. Rio de Janeiro: Abril, 2004.

STEINER, G. As idéias de Heidegger. São Paulo: Cultrix, 1990.

Recebido em: 12 setembro de 2010 Aceito em: 10 de outubro de 2012 
